\title{
On Performance Appraisal for Sales Staff in Pharmaceutical Companies
}

\author{
Yongzhong $\mathrm{Liu}^{1}$, Kening Wang ${ }^{1}$, Haibo $\mathrm{Wu}^{1}$, $\mathrm{Li} \mathrm{Wu}^{2}$ \\ ${ }^{1}$ School of Economics and Management, Jiangxi University of Traditional Chinese Medicine, \\ Nanchang, 330077, China \\ ${ }^{2}$ Jiangxi Province Shanggao County People's Hospital, Shanggao, 336400, China
}

Keywords: Pharmaceutical companies, Sales staff, Performance appraisal

\begin{abstract}
Sales staff in pharmaceutical companies plays an important role in the entire business activity. Effective improvement of work performance of sales staff and scientific performance appraisal, can not only motivate sales team, mobilize enthusiasm and initiative of sales staff, but also help pharmaceutical companies to obtain operating profit and achieve sales targets. This paper discusses and analyzes the status of performance appraisal in pharmaceutical companies, and puts forward improvement suggestions and supporting measures, so as to provide a reference for performance appraisal for sales staff in pharmaceutical companies.
\end{abstract}

\section{Introduction}

China's new medical reform plan proposed to invest 850 billion Yuan for the health care system reform, which provides a huge market space for the pharmaceutical market ${ }^{[1]}$. Most modern pharmaceutical companies use sales-oriented management and organization, so pharmaceutical sales directly determines the realization of corporate profits and strategic goals. Pharmaceutical sales staff is responsible for promotion of drugs, and they also need to establish marketing channels and terminal system in a specific area of sales, responsible for pre-market development, marketing and sales outstanding for the entire process ${ }^{[2]}$. Therefore, performance appraisal system for sales staff is essential for pharmaceutical companies, directly determining economic benefits and long-term development of pharmaceutical companies. So comprehensive and objective performance appraisal for sales staff is necessary to stimulate the enthusiasm and challenge of sales staff, and continuously improve working performance of sales staff and continuous development of companies.

\section{Status of performance appraisal for sales staff in pharmaceutical companies and analysis}

Current appraisal system has one-sided appraisal indicators, vague standards and irrational weighting of indicators, inadaptable to corporate strategies and development change. At present, performance appraisal for sales staff developed by many pharmaceutical companies is only concerned about sales volume or achievement rates, and appraisal indicators design emphasizes on quantitative sales targets, leading to that target of sales staff is to maximize their sales, only focusing on short sales, but ignoring the long-term business benefits. Vague performance appraisal criteria often lead subjective judgment from appraisers, resulting in partiality of appraisal results, which is easy to thwart the enthusiasm of sales staff.

The appraisal method is simple, appraisal subject is single, and personnel in charge of appraisal are not professional. In many pharmaceutical companies, the performance appraisal is often only from superiors of sales staff, not from peers, subordinates or internal and external customers. Superiors are difficult to fully understand all subordinates; therefore there must be some one-sided and subjective appraisal results. Scientific performance appraisal is involved with multifaceted appraisal items, and unscientific appraisal method will lead to bias, resulting in complaint, dissatisfaction emotion and a heavy blow of enthusiasm. Performance appraisal for sales staff should consider both superior-level and customer-level.

Result-centered appraisal content leads to utilitarian behaviors of sales staff. Some sales men are often unscrupulous to achieve sales targets, such as abuse of rebates, transregional sales at low price, 
even unrealistic overstock for commercial companies and hospitals, resulting in extremely confusing sales market order and serious overstock, adverse to sustainable development of companies.

Appraisal process lacks enough communication. If managers responsible for performance appraisal do not fully understand the real purpose of performance appraisal, and appraisers do not have much professional knowledge about performance appraisal, performance appraisal will become formalistic, just concerned about scores and attendance rate. Performance communication should involve managers and subordinates, to achieve their goals and facilitate the completion of tasks. In current pharmaceutical companies, from the development and decomposition of initial performance goals, to feedback and improvement of final performance results, two-way interactive communication is insufficient in the whole process, and performance communication is just the unilateral act of managers.

Appraisal results lack feedback mechanism. At present, performance appraisal manager in many pharmaceutical companies often do not pay enough attention to performance appraisal results. Performance appraisal results are first-hand and the truest information reflecting the status of the company performance and also helping superiors well inspect subordinates. Furthermore analysis on the results can facilitate companies to find problems encountered by employees in the work and also provide appropriate training and guidance to promote the unified development of goals of companies and employees. The main purpose of the appraisal feedback is to find out problems of appraised employees through face to face communication, propose improvement plan to improve the work performance of employees, and promote the common development of employees and companies ${ }^{[3]}$.

\section{Improve performance appraisal for sales staff in pharmaceutical companies}

\section{Effectively implement performance appraisal work and performance appraisal management}

Firstly, we must strengthen the responsibility sense of appraisers, who should stick to justice, fairness and openness, with a high degree of professional dedication and pragmatic attitude to perform their duties, to complete the appraisal tasks and ensure effective implementation of the appraisal work; secondly, strengthen records. Leave relevant appraisal records as evidences to convince people. Personnel mainly responsible for appraisal should adhere to "evidence first", and provide relevant instructions or explanation for reward or penalty points to ensure the fairness and rigor of performance appraisal ${ }^{[4]}$. In addition, in order to ensure smooth implementation of performance appraisal for sales staff, it is necessary to ensure unity thinking of sales staff in pharmaceutical companies, thus guarantee consistent action of sales staff.

\section{Set scientific performance indicators}

Firstly analyze corporate strategic goals and periodical goals, then use key performance indicators (KPI) method, balanced scorecard (BSC) and other tools to break down actions to be taken by companies, extract core appraisal indicators, decompose all-level performance indicators to relevant departments, and then gradually into various positions, to ensure support of key performance indicators to achieve strategic goals. BSC is an indicator system based on corporate strategic goals and it is a very effective performance management tool. Based on business strategies, BSC comprehensively appraise and manage companies from four perspectives, including finance, customer, internal business processes, learning and growth. BSC can help management to convert corporate strategies and development goals into a set of coherent performance appraisal indicators, not only like other appraisal methods able to objectively appraise the current state of corporate business and management, but also appraise driving factors of corporate future development from four perspectives, including finance, customer, internal business processes, learning and growth, accurately analyze these driving factors, timely adjust business and management strategies to ensure that companies are in accordance with strategic development goals. KPI is the product of 2-8 principle and management by objectives, and is a commonly-used tool for implementation of performance appraisal. Based on 20\% key performance indicators, control and guide $80 \%$ corporate 
performance. Decompose corporate strategic goals and find out key strategic goals, promote decomposition of key performance indicators of companies, departments and positions from strategic goals. KPI can simplify performance appraisal, quantitatively present critical success factors of performance appraisal, and promote successful implementation of performance appraisal.

\section{Adjust appraisal criteria in due time}

Make rational and timely adjustment and follow-up for all appraisal criteria. Selling situation of pharmaceutical companies change with the economic environment, seasonal changes, and market areas, therefore performance appraisal criteria should be adjusted based on different economic situations, seasons and regions. In addition, the performance appraisal cycle needs to be combined with the actual situation of companies. According to related theory about performance appraisal, performance appraisal cycle should not be designed to be too short or too long. Too short cycle will increase management costs, but also inflict psychological burden of employees; too long cycle makes employees underestimate the role of performance appraisal, so performance appraisal will become formalistic and does not play its due role.

\section{Pharmaceutical business managers must pay attention to performance appraisal for sales staff, to lay ideology and publicity foundation to form the performance culture}

At the same time, prepare a reasonable structure, standardized job analysis and job design, clear division of processes and responsibilities, and even clear strategies and visions common recognized by employees. Performance appraisal should be able to stimulate personal growth and development of companies. Appraisers shall strengthen propaganda and focus on communication with appraised employees, to make them understand performance appraisal is based on respecting values of employees, eliminate and clarify misconceptions about performance appraisal. We should focus on creating a culture atmosphere with seamless communication.

\section{Establish performance incentive system adaptable to performance appraisal}

According to performance appraisal results of sales staff, determine the reasonable salary incentive. In the design of the performance appraisal system, design performance-related salary system for sales staff according to characteristics of pharmaceutical companies. Salary incentives is not just basic salary plus commission, also includes a variety of incentives, such as wage increase, bonus reward, promotion, opportunities to participate in learning or training, going out for visit or vacation, recognition or praise from the top as well as a variety of benefits, honors, and challenging responsibilities. Overall, pay attention to demands of employees and play the incentive role of salary. On the basis of basic survival needs of sales guaranteed, consider the proportion of bonuses. Motivate sales staff to bring more benefits to the company by increasing bonuses ${ }^{[5}$ ]. While expanding new markets, sales staff faces new businesses, and certainly there exists performance difference. We should objectively appraise working conditions of sales staff and combine with their working characteristics to give rewards and penalties under the condition of differentiating sales performance, in order to fully reflect the fairness and incentive. The author proposes the implementation of performance-oriented salary model,

Sales staff standard monthly salary = basic salary (including skill-based pay and seniority pay) + monthly performance salary + allowances and subsidies

Sales staff annual salary = annual base salary (including skill-based pay and seniority pay) + annual performance salary+ allowances and subsidies +year-end bonuses

For older employees, appropriately increase the percentage of basic salary in order to ensure basic life, reflect advantages of older employees, and increase stability; add new skill-based pay items, set up different levels and determine the level by appraisal. Skill-based pay reflects the contribution of excellent old employees to the company, and also stimulates the enthusiasm of outstanding new employees. For sales positions, sales performance is the most important. In reality, some new employee have stronger work motivation and better sales performance than old employees, but because of short working time and low seniority pay, salaries are not satisfied. Therefore, set up 
skill-based pay to simulate motivation of talented employees. Pharmaceutical production companies should follow the principle of "integrating employment, management, appraisal, salary distribution", combing, integrate, complement and complete salary management system, ensure good convergence of all aspects, and then realize unified planning, unified standards, unified pace, unified management by HR Department ${ }^{[6]}$.

\section{Set performance appraisal supporting mechanism for sales staff in pharmaceutical companies to provide reliable protection}

We can work out all-level sales position description, developed by the HR Department through professional approach after careful research, to provide the basic content and standards for appraise work. Position description provides requirements and standards related to knowledge, quality, skills and other aspects for completion of all works, so we can clearly understand the specific responsibility and content of specific positions. Position description covers the full information about specific position: basic service conditions, working content and responsibilities, leader-member relationship, authority extent, direction of development and so on. Through detailed analysis on the position description, it is possible to design a competency model for specific positions, establish key performance indicators and criteria, and make appraisal work more objective and standard ${ }^{[7]}$. On the other hand, develop complaint mechanism. If employees feel indicators, process, or results of appraise have problems, they can put forward various objections and suggestions through normal processes, and managers can always hear the voices of employees, grasp thoughts of employees, which will help to improve the fairness and authority of performance appraisal, resolve differences between managers and subordinates, obtain support and advocacy of all-level employees. It can ease conflicts between both parties of performance appraisal, and give pressure and constraints to appraisers. It can relieve contradictions and conflicts, to ensure the smooth progress of performance appraisal. Only through the virtuous cycle of performance appraise - performance complaint performance feedback - repeated adjustment- performance re-appraisal, can the performance appraisal purposes be truly realized ${ }^{[8]}$.

\section{Conclusions}

Sales staff is the benefit creator of pharmaceutical companies, and the basis of survival and development of pharmaceutical companies. Effective performance appraisal for sales staff in pharmaceutical companies, reasonable and dynamic adjustment of performance appraisal indicators according to the actual situation of development of pharmaceutical companies, establishment and improvement of the performance appraisal system, not only can improve the performance of sales staff, mobilize their enthusiasm and initiative, but also help achieve sustainable development of pharmaceutical companies.

\section{Acknowledgments}

This paper belongs to the project of Jiangxi Provincial Health Department. Project name: On Marketing Personnel Training Model Based on Characteristics of Traditional Chinese Medicine Taking Jiangxi Province as an Example; Number: 2013A194

\section{References}

[1] Zou Xiaoyan. Study on Optimization of Performance Management System for Sales Staff in BS Pharmaceutical Company . Tianjin University, 2008.

[2] Gu Hai, Lei Ting, Di Tiewei. On Pharmaceutical Marketing Talents Training of 21st Century. Journal of Nanjing Medical University, 2004 (2): 103-105.

[3] Xu Yi. Review on Theory of Management by Objectives. Foreign Economics and Management, 2006 (09): 9-10. 
[4] William Redmond, Thomas, Mao Ruili. Organizational Performance. (Zan Weimao). Beijing: Economic Management Press, 2011.

[5] Xu Fang Teng. How Scientifically and Effectively Conduct Performance Appraisal for Sales Staff . Strait Pharmaceutical Journal, 2007 (12).

[6] Tian Xueli. Study on Performance Appraisal for Marketing Staff in Pharmaceutical Industry Tianjin: Tianjin University of Commerce, 2010.

[7] Jin Long. Study on Performance Appraisal for Marketing Staff in BC Dragon Pharmaceutical Co., Ltd. . Northwestern University 2012

[8] Gu Huapu. On Construction of BSC and KPI-based Performance Appraisal System for Sales Staff in Pharmaceutical Companies. Hunan University of Technology, 2013 